\title{
The Cech Symposium: A celebration of 25 years of ribozymes, 10 years of TERT, and 60 years of Tom
}

\author{
QUENTIN VICENS, ${ }^{1,2}$ MARY ANN ALLEN, ${ }^{3}$ SUNNY D. GILBERT, ${ }^{2}$ BORIS REZNIK, ${ }^{3}$ \\ ANNE R. GOODING, ${ }^{1,2}$ and ROBERT T. BATEY ${ }^{2}$ \\ ${ }^{1}$ Howard Hughes Medical Institute, University of Colorado, Boulder, Colorado 80309-0215, USA \\ ${ }^{2}$ Department of Chemistry and Biochemistry, University of Colorado, Boulder, Colorado 80309-0215, USA \\ ${ }^{3}$ Molecular, Cellular, and Developmental Biology, University of Colorado, Boulder, Colorado 80309-0215, USA
}

\begin{abstract}
The Cech Symposium was held in Boulder, Colorado, on July 12-13, 2007, to celebrate a triple anniversary: 25 years since the first publication reporting RNA self-splicing, 10 years since the identification of reverse transcriptase motifs in the catalytic subunit of telomerase, and 60 years since the birth of Thomas R. Cech. Past and present members of the Cech laboratory presented on their current research, which branched into many categories of study including RNA-mediated catalysis, telomerase and telomeres, new frontiers in nucleic acids, alternative splicing, as well as scientific research with direct medical applications.
\end{abstract}

Keywords: TERT; ribozyme; splicing; telomerase; telomere

\section{INTRODUCTION}

"It is the people who make these days fabulous," Tom Cech concluded in his opening remarks at the Cech Symposium that took place this past July at the University of Colorado in Boulder. Current and former Cech laboratory members, many of whom have become highly regarded in various fields of scientific and medical research, as well as colleagues, various RNA researchers, and friends, gathered around Tom Cech to celebrate his discoveries of ribozymes (Tom's first publication on catalytic RNAs was in 1982) (Kruger et al. 1982) and of the telomerase reverse transcriptase (TERT) (Tom's laboratory discovered TERT in 1997) (Lingner et al. 1997), as well as his 60th birthday (Fig. 1).

In the keynote address, Olke Uhlenbeck (Northwestern University) reviewed the history of Tom's career. After Tom completed his graduate studies in the laboratory of John Hearst at the University of California, Berkeley, and his post-doctoral training with Mary Lou Pardue at the Massachusetts Institute of Technology, he was recruited to the University of Colorado, Boulder. In his first years as an Assistant Professor, Tom and his laboratory members discovered self-splicing RNA. In 1989, Tom was awarded

Reprint requests to: Quentin Vicens, Howard Hughes Medical Institute, University of Colorado, Boulder, CO 80309-0215, USA; e-mail: quentin.vicens@colorado.edu; fax: (303) 492-6194.

Article published online ahead of print. Article and publication date are at http://www.rnajournal.org/cgi/doi/10.1261/rna.910008. the Nobel Prize in Chemistry for this discovery (Fig. 2). Tom's philosophy in research and teaching was summarized by Art Pardi (University of Colorado, Boulder) using a few simple words: "If you do something, do it well." Tom further emphasized in his overview that his goal as a scientist is to always pursue rigorous science that has a significant impact on the field.

Seminal discoveries in his laboratory, for example, the group I intron ribozyme (Kruger et al. 1982), TERT (Lingner et al. 1997), and the protection of telomeres (POT-1) protein (Baumann and Cech 2001), have launched new exciting areas in biological research, which was beautifully illustrated by the exceptional results presented by past and current laboratory members during this symposium (a detailed program as well as a selection of presentations and pictures are available at http://cechlab.colorado.edu). The Cech symposium revealed how Tom's impact on modern science resonates through the extraordinary work of his students, post-doctoral fellows, laboratory staff members, and colleagues. This influence is felt in many fields of research including RNA-mediated catalysis, new frontiers in nucleic acids, alternative splicing, telomerase and telomeres, as well as scientific research with direct medical applications.

\section{CATALYTIC RNA}

Since the discovery of a group I ribozyme in Tetrahymena thermophila 25 years ago, many more ribozymes have been 

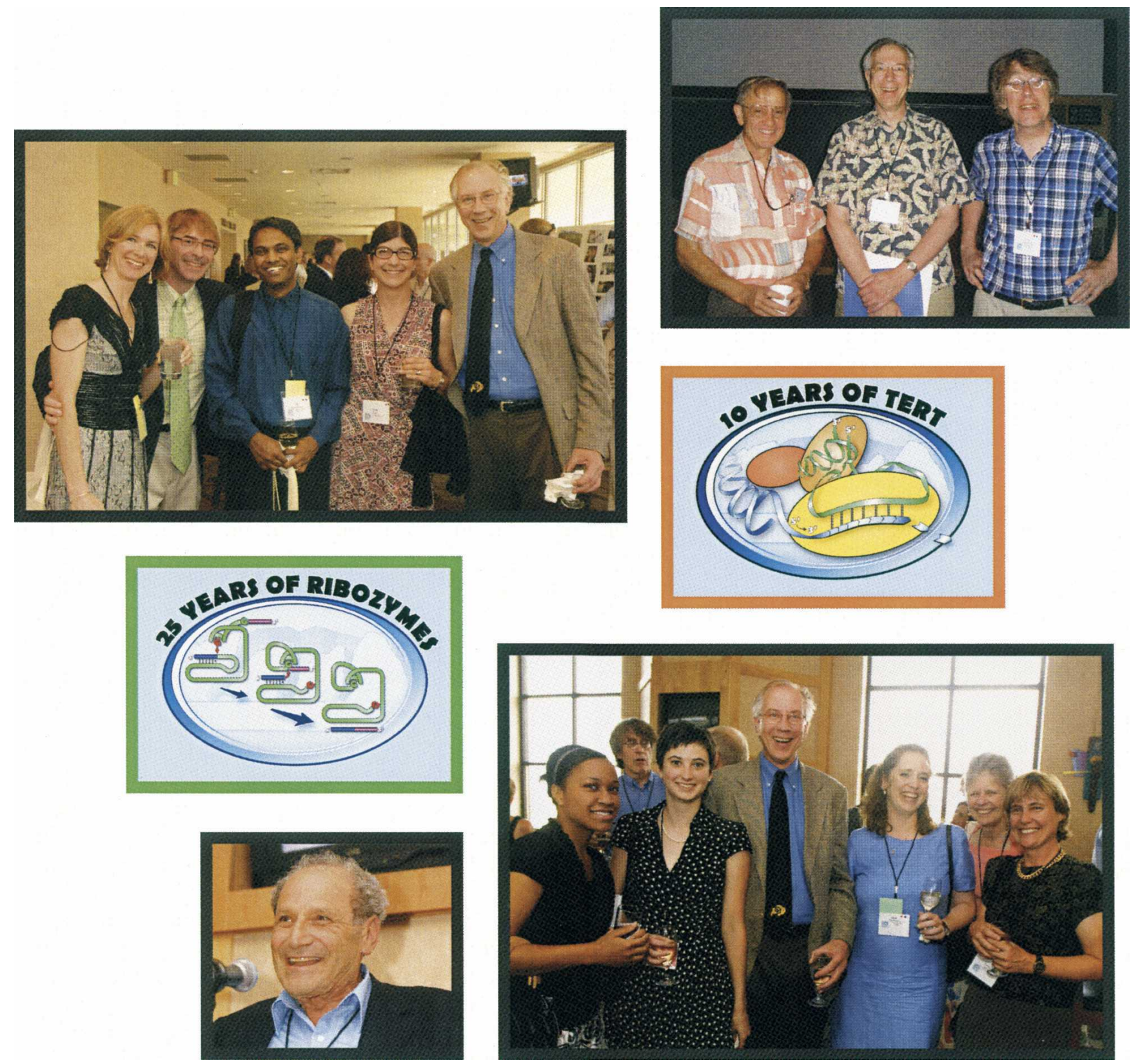

FIGURE 1. Tom Cech surrounded by past and current laboratory members and colleagues during the Cech Symposium. (Top left, from left to right) Jennifer Doudna (former post-doctoral fellow), Joe Piccirilli (former post-doctoral fellow), M.K Raghuraman (former graduate student), Marty Fedor (former Uhlenbeck graduate student), Tom Cech. (Top right, from left to right) Marv Caruthers (current colleague), Tom Cech, Olke Uhlenbeck (former colleague). (Bottom left) John Hearst (Tom Cech's Ph.D. advisor). (Bottom right, from left to right) Jessica McGrath (summer student), Olke Uhlenbeck (former colleague, at the back), Chrysa Latrick (graduate student), Tom Cech, Anne Gooding (staff scientist), Joan Steitz (former visiting scientist), Anna-Marie Pyle (former post-doctoral fellow). Photo credit: Larry Harwood, University of Colorado. Artwork: Blake Porch, HHMI Headquarters.

discovered in nature or through in vitro selection. One exciting recent discovery is that the ribosome is a ribozyme (Steitz and Moore 2003). High-resolution structures of ribosomal subunits and complete ribosomes revealed a catalytic core devoid of proteins (Nissen et al. 2000; Yusupov et al. 2001). Breakthroughs about the relationship between ribosome structure and function revived deeper mechanistic problems. The speakers discussed two main questions: How do ribosomal particles form and how does the ribosome catalyze peptide bond formation? Jamie Williamson (Scripps Research Institute) is focusing on ribosome assembly. Using a combination of mass spectrometry and in vivo studies, he demonstrated that no step along the assembly pathway of the $30 \mathrm{~S}$ subunit is rate 


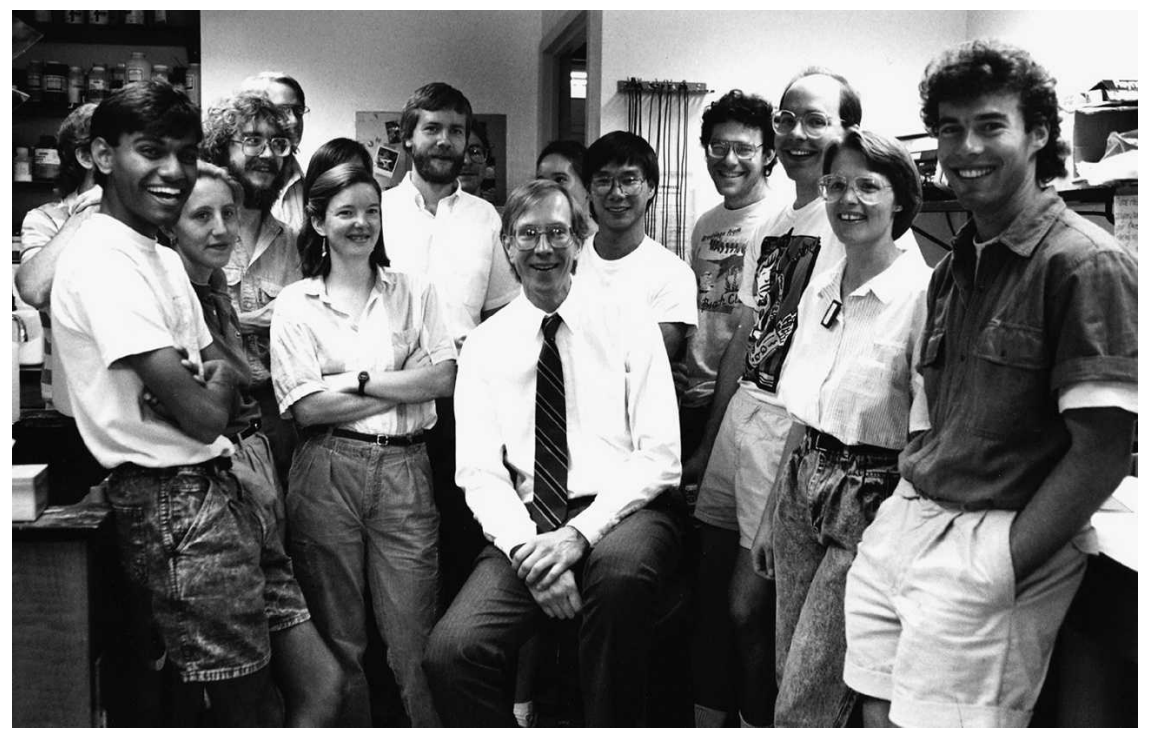

FIGURE 2. Tom Cech and his laboratory members soon after the announcement of the 1989 Nobel Prize in Chemistry. (From left to right) M.K. Raghuraman, Will Downs (behind M.K.R.), Alexandra Gampel, Jamie Williamson, James McSwiggen, Felicia Murphy, Jennifer Davila-Aponte (behind F.M.), Art Zaug, Joe Piccirilli, Tom Cech, Sarah Woodson, Ben Young, Dan Herschlag, Dan Celander, Cheryl Grosshans, Brian Hicke.

limiting (Talkington et al. 2005; Williamson et al. 2005). In short, assembly occurs by alternating series of RNA conformational changes and protein binding events that create a folding landscape devoid of kinetic traps. Also studying the assembly of the ribosome, Sarah Woodson (Johns Hopkins University) used time-resolved footprinting to reveal that the assembly of the $30 \mathrm{~S}$ particle relies on local RNA-RNA interactions and on the binding of ribosomal proteins in a stochastic manner (Adilakshmi et al. 2006). Complementing the talks on ribosomal assembly, Scott Strobel (Yale University) presented a detailed structural and enzymatic investigation of the ribosomal petidyl-transferase mechanism. He showed evidence that inside the metal-free active site of the ribosome, proton shuffling is assisted by the $2^{\prime}$-hydroxyl group of the $3^{\prime}$-nucleotide of the P-site tRNA (Weinger and Strobel 2007). Strobel concluded that proton shuffling is the primary mechanism for catalysis of peptide bond formation. Taken together, the results of Williamson, Woodson, and Strobel give a clearer picture of how the ribosome is formed and how it functions.

In contrast to being tRNA assisted, catalysis by the group I intron involves metal ions (Cech et al. 1992; Piccirilli et al. 1993). The Strobel laboratory observed the location of key metal ions in two crystal structures of the Azoarcus group I intron (Stahley and Strobel 2005; Stahley et al. 2007). By capturing this ribozyme in two distinct states along the selfsplicing reaction (before and after the second transesterification), these structures enable a comparison of the positions and the roles of the metal ions and their ligands in the catalytic site. To end this first session, Phil Bevilacqua (Pennsylvania State University) and collaborators (includ- ing Barbara Golden, Purdue University, a previous post-doctoral fellow from the Cech laboratory) showed that just like amino acid side chains in proteins, nucleobases can catalyze reactions. Applying the novel technique of Raman crystallography to the hepatitis delta virus ribozyme, he demonstrated that the proton transfer mechanism involves an active site cytosine with a shifted $\mathrm{pKa}$ serving as a general acid (Nakano et al. 2000; Bevilacqua and Yajima 2006). This much anticipated result deepens our knowledge of the chemical functionality associated with the building blocks of RNA.

\section{NEW FRONTIERS IN NUCLEIC ACIDS}

Several former members of Tom's laboratory are expanding the frontiers of nucleic acid science in two ways: by identifying new facets of gene expression regulation and by developing new methods and artificial functions for nucleic acids. Dan Herschlag (Stanford University) examines post-transcriptional regulation of eukaryotic gene expression by RNA binding proteins and how regulation has evolved during speciation. In collaboration with Pat Brown (Howard Hughes Medical Institute, Stanford University) he identified, using DNA microarrays, a class of regulatory proteins called Puf proteins. Puf proteins specifically bind and segregate mRNAs according to their gene product function and subcellular localization (Gerber et al. 2004). These results suggest a correlation between the diversity of proteins that organize gene expression in a spatial and sequential manner and increased organism complexity (Keene 2007). In eukaryotes, genes can also be regulated through a mechanism involving microRNAs (miRNAs). Feng Guo (University of California, Los Angeles) proposed how miRNA processing may be linked to signaltransduction pathways. The Guo group discovered a hemepromoted dimerization of Pasha, a double-stranded RNA binding protein. The heme-bound Pascha is more active in miRNA maturation when complexed with the ribonuclease Dicer. Hence, modulation of miRNA processing by cellular metabolites may allow regulation of biosynthetic genes in mammalian cells (Faller et al. 2007). Understanding regulatory mechanisms of gene expression, whether mediated by miRNAs, Puf proteins, or other factors, requires inventive tools to look closely at the basic gene building blocks.

The efforts of Kevin Weeks (University of North Carolina, Chapel Hill) and Scott Silverman (University of Illinois at Urbana-Champaign) have expanded the diversity 
of tools available for looking into nucleic acid structure and function. With a novel 2' -hydroxyl modification chemistry, the Weeks laboratory investigates the "SHAPE" (selective 2 '-hydroxyl acylation analyzed by primer extension) of RNA (Merino et al. 2005; Mortimer and Weeks 2007). This technique can be used for high throughput analysis of RNA structure and reveals in a single experiment structured regions of an RNA molecule at the nucleotide level. As an example, the analysis of the $5^{\prime}$ end of the HIV-1 RNA yielded both previously mapped and newly identified structured regions with yet to be determined functions (K.A. Wilkinson, J.M. Watts, R.J. Gorelick, and K.M. Weeks, unpubl.).

Understanding catalysis by DNA rather than RNA and developing tools based on these artificial DNA enzymes is a major research focus of the Silverman laboratory. DNA enzymes are selected in vitro to selectively cleave and ligate RNA molecules (Höbartner and Silverman 2007a). Among other functions, these deoxyribozymes can be used to attach FRET probes to RNAs through a process called DECAL (deoxyribozyme-catalyzed labeling) (Baum and Silverman 2007). In the future, deoxyribozymes may be broadly useful catalysts for promoting the formation of protein-RNA, sugar-RNA, and protein-sugar linkages (Höbartner and Silverman 2007b), including the use of small-molecule substrates in place of oligonucleotides (Höbartner and Silverman 2007b). Clearly, the only boundaries to how nucleic acids can be studied are set by our imagination, and this session showed how the use of our knowledge in chemistry can be applied to creating new tools that will lead us to a better appreciation of nucleic acid structure and function.

\section{ALTERNATIVE SPLICING}

As catalytic mechanisms of mRNA processing have always been at the heart of research in the Cech laboratory, it is no surprise that former members of the laboratory have continued to make important discoveries in the field of alternative splicing. Kara Juneau (Stanford University School of Medicine) studies the purpose of introns. She indicated that in yeast, intron-containing genes produce more RNAs and proteins than intron-deprived genes (Juneau et al. 2006). Using a genome-wide assay for mapping introns in Saccharomyces cerevisiae, she discovered nine new introns in addition to the 18 previously predicted ones. One of these may provide the first example of alternative splicing in S. cerevisiae (Juneau et al. 2007). While Juneau researches the roles of introns, Don Rio (University of California, Berkeley) investigates how alternative splicing occurs and the factors involved. The specificity of the four Drosophila melanogaster homologs of the RNA-binding proteins hnRNPA/B were examined using microarrays and SELEX. Rio discovered that each protein recognizes different splice sites, and he showed that cer- tain hnRNP proteins are therefore more likely to bind to introns while others bind preferentially to exons. This information may give clues to their functions in alternative splicing.

Coming from a different angle and studying another organism, Paula Grabowski (University of Pittsburgh) uses neuronal cells to investigate the regulation of alternative splicing. Her laboratory studies an exon that is proposed to communicate signals from the membrane to the nucleus during neuronal activity. This exon is differentially spliced in response to specific stimuli. A silencer motif in the mRNA (in which the number of copies of a UAGG repeat varies) and several protein splicing factors control the splicing of the exon cassette (An and Grabowski 2007). Taken together, these three speakers offered new insights into some of the most burning questions regarding the events that directly and indirectly lead to or follow splicing.

\section{TELOMERASE AND TELOMERES}

Current research on telomerase and telomeres focuses on the structure-function relationships of two major players: the RNA component of the telomerase and the proteins located at the end of the telomere. The RNA component of telomerase provides the template for reverse transcription as well as binding sites for essential and accessory proteins (Chen and Greider 2004; Zappulla and Cech 2006). Outside of the protein binding elements in the RNA, sequence elements show little conservation; however, protein binding elements are highly conserved. Both by separately repositioning two protein binding sites in the $S$. cerevisiae telomerase RNA to several new locations and by creating a mini-telomerase RNA that retains telomerase function and cell viability, David Zappulla (University of Colorado, Boulder) provided evidence that the RNA serves as a flexible scaffold to bring together telomerase protein subunits (Zappulla and Cech 2004; Zappulla et al. 2005). In a complementary study, Mike Jarstfer (University of North Carolina, Chapel Hill) used the SHAPE chemistry developed by the Weeks laboratory to analyze the structure of the Thermus thermophila telomerase RNA both before and after TERT holoenzyme assembly (J.D. Legassie and M.B. Jarstfer, unpubl.). Upon protein binding, the RNA undergoes conformational changes in the template and the pseudoknot regions. The structure of a stem-loop that is essential for activity and processing was obtained by SHAPE mapping; notably, this structure is consistent with that determined by NMR (Chen et al. 2006).

Even though these secondary structures cast light on the mechanisms that allow for maintenance of chromosome integrity, many aspects of this process remain obscure. A subset of the former members of the Cech laboratory continues to study the functions of proteins and RNAs that have a role in telomere maintenance. First, more components are being discovered that are part of the machinery located at the telomere. For example, Peter 
Baumann (Stowers Institute for Medical Research) recently identified a fission yeast telomerase RNA subunit gene (ter $1+$ ) in Schizosaccharomyces pombe, after many years of looking for it (Leonardi et al. 2008). In knockout mutants that lack this gene, significant telomere length shortening was observed, and the surviving organisms eventually joined their chromosome ends. Additionally, Joachim Lingner (Swiss Federal Institute of Technology) presented the discovery of a new RNA that colocalizes with telomeres and telomerase. This RNA contains telomeric repeats as well as other telomeric sequences, and preliminary investigations indicate that this RNA could link telomere maintenance and nonsense mediated mRNA decay (Azzalin et al. 2007).

Many proteins bind to the end of chromosomes in order to protect them from degradation as well as regulate telomere end extension (Croy and Wuttke 2006; Wang et al. 2007). Ming Lei (University of Michigan) presented an extensive structural analysis of the proteins that cap the end of mammalian telomeres by forming the shelterin complex. Cocrystal structures of these various proteins bound to short peptides belonging to their partners (such as TRF1 and TRF2 bound to a peptide from TIN2) revealed how a new family of conserved modules mediates protein-protein interactions at telomeres (Chen et al. 2008). Carolyn Price (University of Cincinnati) showed that another of these proteins, POT-1, negatively regulates telomere length, likely through competition with telomerase for the chromosome end (Churikov et al. 2006). She also concluded that, during the cell cycle, POT-1 mediates an essential checkpoint in Tetrahymena (Jacob et al. 2007). Finally, Julia Cooper (Cancer Research UK) discussed how telomere-associated proteins are necessary for proper chromosome segregation during meiosis in $S$. pombe. In early meiosis, chromosome ends gather at the nuclear envelope near the spindle pole body forming a structure called the "telomere bouquet" (Tomita and Cooper 2007). Formation of the telomere bouquet is necessary for proper sorting and separation of homologous chromosomes during the early stages of meiosis. These presentations illustrated how populated the end of the telomeres can be, and that the multiple partners present can be involved in various mechanisms other than the addition of telomeric repeats.

\section{RNA PLUS}

Several past members of the Cech laboratory now focus on the practical application of scientific advances in medicine and health care. Because of their implication in genetic diseases and cancer, the outcomes of genomic instability are under scrutiny by John Hearst (Tom's graduate advisor) and by Dan Gottschling (one of Tom's first graduate students). Hearst (University of California, Berkeley) discussed the need to blur the lines between scientific exploration and clinical practice so that questions pertaining to how chromosome translocations result in spon- taneous abortion, abnormal births, and cancer can be addressed. A higher sequence resolution necessary for the identification of genomic regions that have experienced breaks, translocations, and other abnormalities can be made by combining DNA banding techniques and chromosome microdissection (S. Liao, J.E. Hearst, J. Yu, D. Pinkel, and Z. Qi, unpubl.). Expanding on the nature of genomic instability, the Gottschling laboratory (Fred Hutchinson Cancer Research Center) studies the link between increasing age and the incidence of cancer. Using S. cerevisiae as a model system, he showed that genomic instability, as measured by a loss of heterozygosity $(\mathrm{LOH})$, increases in the daughters of the oldest mother cells (McMurray and Gottschling 2003). An innovative screen for genes provoking $\mathrm{LOH}$ identified a nuclear protein involved in DNA recombination and repair that plays an additional role in aging. This protein is more diffuse in older cells, likely a result of its aberrant targeting to the cytoplasm. Such a mistargeting prevents this nuclear protein from performing its function in genome maintenance, thus increasing the risk of cancer (D. Andersen, L.L. Carr, D.L. Lindstrom, and D.E. Gottschling, unpubl.).

Using a different approach, Guowei Fang (Stanford University) studies genomic instability and has made several discoveries about mitotic checkpoints in mammalian cells (Kang et al. 2002; Seki and Fang 2007). For example, a novel method for identifying mitotic regulators revealed a ubiquitin ligase that inhibits the activity of a kinase that controls chromosome segregation (Plk1), thus delaying entry to mitosis. Fang suggested that this control may be undermined in tumorigenesis. By improving our understanding of human deficiencies at the cellular and molecular level, these three approaches are opening the door to the further development of anti-cancer therapies.

After the discoveries of antisense RNAs and ribozymes, RNA has been seen as a promising therapeutic agent or target in treating cancer and other major health problems (Sullenger and Gilboa 2002; Foloppe et al. 2006). It is possible, for example, to select for RNAs that recognize a specific protein and inhibit its function; these RNAs are known as aptamers (Ellington and Szostak 1990; Tuerk and Gold 1990). Bruce Sullenger (Duke University Medical Center) discussed two successful applications of aptamers for medical treatments: their application as artificial activators of receptors located on the surface of prostate cancer cells to induce an antibody-like immune response and as delivery agents of siRNAs (McNamara et al. 2006). A chimeric RNA composed of an siRNA to the Plk1 kinase and an aptamer known to target a cell-surface receptor overexpressed in prostate cancer cells yielded a molecule that could be specifically targeted to a cancer cell in order to regress tumor growth. This chimeric RNA is now in phase 1 clinical trials.

Another way to combat disease is to focus on improving the drug prescription knowledge base, as well as the 
effectiveness and the specificity of known drugs. Ben Young (Rose Medical Center, University of Colorado, Denver) presented statistics on current drug treatments for HIV and the use of pharmacogenomics to decide which drugs will be most effective on individual patients, based on their genetics and alternative medical conditions. However there are still unmet needs, such as that of drugs that can be used when patients have both an HIV infection and other conditions such as tuberculosis or various sexually transmitted diseases (http://www.thebody.com/content/art39616. html). Using a molecular approach, Phil Hammond at Xencor (Monrovia, CA) creates better therapeutic agents to target different types of tumors of the lymphatic system. Specific mutations to "humanize" antibodies obtained from mice allowed Hammond and coworkers to increase the potency, the expression, and the half-life of existing antibodies and to decrease their cytotoxicity (Lazar et al. 2007). In developing treatments for medical conditions, this group of past members of the Cech laboratory are positively affecting current health care efforts while attempting to make a difference in the scientific community today.

\section{CONCLUDING REMARKS}

Although serendipity often strikes in science, a good scientist recognizes an unexpected result as an opportunity to make a discovery that could launch a new field. The variety of topics covered at the Cech Symposium illustrates the depth of Tom's impact in science, directly through his own research and indirectly through the numerous achievements of the people that he has trained over the years. The secret to each accomplishment was, as appropriately summarized by Paula Grabowski, to "follow the results wherever they may lead." We are happy and grateful to be present in such a dynamic era of thrilling breakthroughs and to benefit from Tom's continuing success as a brilliant scientist and a committed mentor. Thank you Tom, and happy birthday!

\section{ACKNOWLEDGMENTS}

We thank Tom Blumenthal, Jeff Kieft, Art Pardi, and the speakers for helpful comments on this manuscript.

\section{REFERENCES}

Adilakshmi, T., Lease, R.A., and Woodson, S.A. 2006. Hydroxyl radical footprinting in vivo: Mapping macromolecular structures with synchrotron radiation. Nucleic Acids Res. 34: e64. doi: 10.1093/nar/gkl291.

An, P. and Grabowski, P.J. 2007. Exon silencing by UAGG motifs in response to neuronal excitation. PLoS Biol. 5: e36. doi: 10.1371/ journal.pbio.0050036.

Azzalin, C.M., Reichenbach, P., Khoriauli, L., Giulotto, E., and Lingner, J. 2007. Telomeric repeat containing RNA and RNA surveillance factors at mammalian chromosome ends. Science 318: 798-801.
Baum, D.A. and Silverman, S.K. 2007. Deoxyribozyme-catalyzed labeling of RNA. Angew. Chem. Int. Ed. Engl. 46: 3502-3504.

Baumann, P. and Cech, T.R. 2001. Pot1, the putative telomere endbinding protein in fission yeast and humans. Science 292: 11711175.

Bevilacqua, P.C. and Yajima, R. 2006. Nucleobase catalysis in ribozyme mechanism. Curr. Opin. Chem. Biol. 10: 455-464.

Cech, T.R., Herschlag, D., Piccirilli, J.A., and Pyle, A.M. 1992. RNA catalysis by a group I ribozyme. Developing a model for transition state stabilization. J. Biol. Chem. 267: 17479-17482.

Chen, J.L. and Greider, C.W. 2004. An emerging consensus for telomerase RNA structure. Proc. Natl. Acad. Sci. 101: 1468314684.

Chen, Y., Fender, J., Legassie, J.D., Jarstfer, M.B., Bryan, T.M., and Varani, G. 2006. Structure of stem-loop IV of Tetrahymena telomerase RNA. EMBO J. 25: 3156-3166.

Chen, Y., Yang, Y., van Overbeek, M., Donigian, J.R., Baciu, P., de Lange, T., and Lei, M. 2008. A shared docking motif in TRF1 and TRF2 used for differential recruitment of telomeric proteins. Science (in press).

Churikov, D., Wei, C., and Price, C.M. 2006. Vertebrate POT1 restricts G-overhang length and prevents activation of a telomeric DNA damage checkpoint but is dispensable for overhang protection. Mol. Cell. Biol. 26: 6971-6982.

Croy, J.E. and Wuttke, D.S. 2006. Themes in ssDNA recognition by telomere-end protection proteins. Trends Biochem. Sci. 31: 516525.

Ellington, A.D. and Szostak, J.W. 1990. In vitro selection of RNA molecules that bind specific ligands. Nature 346: 818-822.

Faller, M., Matsunaga, M., Yin, S., Loo, J.A., and Guo, F. 2007. Heme is involved in microRNA processing. Nat. Struct. Mol. Biol. 14: 23-29.

Foloppe, N., Matassova, N., and Aboul-Ela, F. 2006. Towards the discovery of drug-like RNA ligands? Drug Discov. Today 11: 10191027.

Gerber, A.P., Herschlag, D., and Brown, P.O. 2004. Extensive association of functionally and cytotopically related mRNAs with Puf family RNA-binding proteins in yeast. PLoS Biol. 2: 342-354.

Höbartner, C. and Silverman, S.K. 2007a. Engineering a selective small-molecule substrate binding site into a deoxyribozyme. Angew. Chem. Int. Ed. Engl. 46: 7420-7424.

Höbartner, C. and Silverman, S.K. 2007b. Recent advances in DNA catalysis. Biopolymers 87: 279-292.

Jacob, N.K., Lescasse, R., Linger, B.R., and Price, C.M. 2007. Tetrahymena POTla regulates telomere length and prevents activation of a cell cycle checkpoint. Mol. Cell. Biol. 27: 1592-1601.

Juneau, K., Miranda, M., Hillenmeyer, M.E., Nislow, C., and Davis, R.W. 2006. Introns regulate RNA and protein abundance in yeast. Genetics 174: 511-518.

Juneau, K., Palm, C., Miranda, M., and Davis, R.W. 2007. Highdensity yeast-tiling array reveals previously undiscovered introns and extensive regulation of meiotic splicing. Proc. Natl. Acad. Sci. 104: 1522-1527.

Kang, D., Chen, J., Wong, J., and Fang, G. 2002. The checkpoint protein Chfr is a ligase that ubiquitinates Plk1 and inhibits Cdc2 at the G2 to M transition. J. Cell Biol. 156: 249-259.

Keene, J.D. 2007. RNA regulons: Coordination of post-transcriptional events. Nat. Rev. Genet. 8: 533-543.

Kruger, K., Grabowski, P.J., Zaug, A.J., Sands, J., Gottschling, D.E., and Cech, T.R. 1982. Self-splicing RNA: Autoexcision and autocyclization of the ribosomal RNA intervening sequence of Tetrahymena. Cell 31: 147-157.

Lazar, G.A., Desjarlais, J.R., Jacinto, J., Karki, S., and Hammond, P.W. 2007. A molecular immunology approach to antibody humanization and functional optimization. Mol. Immunol. 44: 1986-1998.

Leonardi, J., Box, J.A., Bunch, J.T., and Baumann, P. 2008. TER1, the RNA subunit of fission yeast telomerase. Nat. Struct. Mol. Biol. 15: 26-33. doi: 10.1038/nsmb1343. 
Lingner, J., Hughes, T.R., Shevchenko, A., Mann, M., Lundblad, V., and Cech, T.R. 1997. Reverse transcriptase motifs in the catalytic subunit of telomerase. Science 276: 561-567.

McMurray, M.A. and Gottschling, D.E. 2003. An age-induced switch to a hyper-recombinational state. Science 301: 1908-1911.

McNamara 2nd, J.O., Andrechek, E.R., Wang, Y., Viles, K.D., Rempel, R.E., Gilboa, E., Sullenger, B.A., and Giangrande, P.H. 2006. Cell type-specific delivery of siRNAs with aptamer-siRNA chimeras. Nat. Biotechnol. 24: 1005-1015.

Merino, E.J., Wilkinson, K.A., Coughlan, J.L., and Weeks, K.M. 2005. RNA structure analysis at single nucleotide resolution by selective 2 '-hydroxyl acylation and primer extension (SHAPE). J. Am. Chem. Soc. 127: 4223-4231.

Mortimer, S.A. and Weeks, K.M. 2007. A fast-acting reagent for accurate analysis of RNA secondary and tertiary structure by SHAPE chemistry. J. Am. Chem. Soc. 129: 4144-4145.

Nakano, S., Chadalavada, D.M., and Bevilacqua, P.C. 2000. General acid-base catalysis in the mechanism of a hepatitis delta virus ribozyme. Science 287: 1493-1497.

Nissen, P., Hansen, J., Ban, N., Moore, P.B., and Steitz, T.A. 2000. The structural basis of ribosome activity in peptide bond synthesis. Science 289: 920-930.

Piccirilli, J.A., Vyle, J.S., Caruthers, M.H., and Cech, T.R. 1993. Metal ion catalysis in the Tetrahymena ribozyme reaction. Nature 361: 85-88.

Seki, A. and Fang, G. 2007. CKAP2 is a spindle-associated protein degraded by APC/C-Cdh1 during mitotic exit. J. Biol. Chem. 282: 15103-15113.

Stahley, M.R. and Strobel, S.A. 2005. Structural evidence for a twometal-ion mechanism of group I intron splicing. Science 309: 1587-1590.

Stahley, M.R., Adams, P.L., Wang, J., and Strobel, S.A. 2007. Structural metals in the group I intron: A ribozyme with a multiple metal ion core. J. Mol. Biol. 372: 89-102.
Steitz, T.A. and Moore, P.B. 2003. RNA, the first macromolecular catalyst: The ribosome is a ribozyme. Trends Biochem. Sci. 28: 411418.

Sullenger, B.A. and Gilboa, E. 2002. Emerging clinical applications of RNA. Nature 418: 252-258.

Talkington, M.W.T., Siuzdak, G., and Williamson, J.R. 2005. An assembly landscape for the $30 \mathrm{~S}$ ribosomal subunit. Nature 438: $628-632$.

Tomita, K. and Cooper, J.P. 2007. The telomere bouquet controls the meiotic spindle. Cell 130: 113-126.

Tuerk, C. and Gold, L. 1990. Systematic evolution of ligands by exponential enrichment: RNA ligands to bacteriophage T4 DNA polymerase. Science 249: 505-510.

Wang, F., Podell, E.R., Zaug, A.J., Yang, Y., Baciu, P., Cech, T.R., and Lei, M. 2007. The POT1-TPP1 telomere complex is a telomerase processivity factor. Nature 445: 506-510.

Weinger, J.S. and Strobel, S.A. 2007. Exploring the mechanism of protein synthesis with modified substrates and novel intermediate mimics. Blood Cells Mol. Dis. 38: 110-116.

Williamson, J.R. 2005. Assembly of the 30 S ribosomal subunit. Q. Rev. Biophys. 38: 397-403.

Yusupov, M.M., Yusupova, G.Z., Baucom, A., Lieberman, K., Earnest, T.N., Cate, J.H., and Noller, H.F. 2001. Crystal structure of the ribosome at $5.5 \AA$ resolution. Science 292: 883-896.

Zappulla, D.C. and Cech, T.R. 2004. Yeast telomerase RNA: A flexible scaffold for protein subunits. Proc. Natl. Acad. Sci. 101: 1002410029.

Zappulla, D.C. and Cech, T.R. 2006. RNA as a flexible scaffold for proteins: Yeast telomerase and beyond. Cold Spring Harb. Symp. Quant. Biol. 71: 217-224.

Zappulla, D.C., Goodrich, K., and Cech, T.R. 2005. A miniature yeast telomerase RNA functions in vivo and reconstitutes activity in vitro. Nat. Struct. Mol. Biol. 12: 1072-1077. 

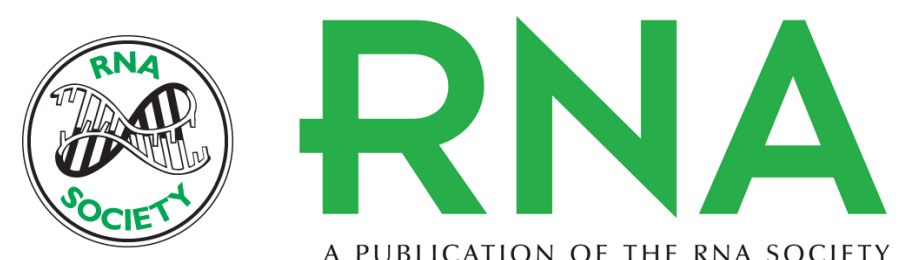

A PUBLICATION OF THE RNA SOCIETY

\section{The Cech Symposium: A celebration of 25 years of ribozymes, 10 years of TERT, and 60 years of Tom}

Quentin Vicens, Mary Ann Allen, Sunny D. Gilbert, et al.

RNA 2008 14: 397-403

References This article cites 48 articles, 18 of which can be accessed free at: http://rnajournal.cshlp.org/content/14/3/397.full.html\#ref-list-1

Open Access Freely available online through the RNA Open Access option.

License Freely available online through the open access option.

Email Alerting Receive free email alerts when new articles cite this article - sign up in the box at the Service top right corner of the article or click here. 